\title{
As perguntas dos estudantes para o ensino de Ciências: um meio de identificar problemas conceituais
}

\section{Las preguntas de los estudiantes para la enseñanza de Ciencias: un medio de identificar problemas conceptuales}

\author{
Simone Mertins (simonemertins@hotmail.com) \\ PUCRS - Pontifícia Universidade Católica do Rio Grande do Sul, Doutoranda no Programa de Pós- \\ Graduação em Educação em Ciências e Matemática. \\ Carla Melo da Silva (carlamelodasilva2015@gmail.com) \\ PUCRS - Pontifícia Universidade Católica do Rio Grande do Sul, Doutoranda no Programa de Pós- \\ Graduação em Educação em Ciências e Matemática.
}

Marcelo Amaral-Rosa (marcelo.pradorosa@gmail.com)

PUCRS - Pontifícia Universidade Católica do Rio Grande do Sul, Estágio Pós-Doutoral no Programa de Pós-Graduação em Educação em Ciências e Matemática.

Maurivan Güntzel Ramos (mgramos@pucrs.br)

PUCRS - Pontifícia Universidade Católica do Rio Grande do Sul, Docente no Programa de PósGraduação em Educação em Ciências e Matemática.

Resumo: Este estudo buscou responder à seguinte pergunta norteadora: De que modo as perguntas propostas por estudantes de Ensino Fundamental e Médio revelam os problemas conceituais que os estudantes têm em relação aos conceitos científicos? Os participantes foram 187 estudantes de quatro turmas de $5^{\circ}$ ano do Ensino Fundamental e de quatro turmas de $2^{\circ}$ ano do Ensino Médio, provenientes de quatro escolas públicas de diferentes cidades do Rio Grande do Sul. Após observarem um experimento em que ocorreu a extinção da chama de uma vela por ação do gás carbônico, os estudantes propuseram 603 perguntas sobre suas dúvidas e interesses em relação ao fenômeno observado. Para esse estudo, o corpus foi recortado, com vistas às perguntas que continham problemas conceituais. Desse modo, analisamos 63 perguntas dos estudantes de Ensino Médio e 40 perguntas dos estudantes de Ensino Fundamental. Essas perguntas foram categorizadas em relação aos problemas conceituais presentes, por meio da Análise Textual Discursiva. Os resultados indicam que, em ambos os níveis de ensino, a forma como a proposição de ensino é executada está falha. Daí a relevância desse estudo, que aponta as perguntas dos estudantes e sua utilização como retomada das abordagens em sala de aula, a fim de sanar as compreensões equivocadas.

Palavras-chave: perguntas dos estudantes; problemas conceituais; ensino de Ciências.

Resumen: Este estudio ha tratado de responder a la siguiente pregunta: ¿De qué manera las preguntas propuestas por estudiantes de primaria y secundaria revelan los problemas conceptuales que tienen los estudiantes en relación con los conceptos científicos? Los participantes fueron 187 estudiantes de cuatro clases de $5^{\circ}$ año de Enseñanza Primaria y cuatro clases de $2^{\circ}$ año de Enseñanza Secundaria, provenientes de cuatro escuelas públicas de diferentes ciudades de Rio Grande do Sul. Después de observar un 
experimento en el que ocurrió la extinción de la llama de una vela por acción del gas carbónico, los estudiantes propusieron 603 preguntas sobre sus dudas e intereses en relación al fenómeno observado. Para este estudio, el corpus fue recortado, con vistas a las preguntas que contenían problemas conceptuales. Se analizaron 63 preguntas de los estudiantes de secundaria y 40 preguntas de los estudiantes de primaria. Las preguntas de los estudiantes fueron categorizadas en relación a los problemas conceptuales presentes, por medio del Análisis Textual Discursiva. Los resultados indican que en ambos niveles de enseñanza, la forma en que se lleva a cabo la proposición de enseñanza, es defectuosa. De ello, se dresprende la relevancia de las preguntas de los estudiantes y su utilización como retomada de los enfoques en aula, a fin de reparar las comprensiones equivocadas.

Palabras clave: Preguntas de los estudiantes; problemas conceptuales; enseñanza de Ciencias.

\section{INTRODUÇÃO}

No ensino de Ciências, é fundamental considerar os estudantes como parte do processo de construção do conhecimento, para isso o aprendizado precisa ser abordado como um processo construtivo de busca de significados e interpretações. Quando isso acontece, os estudantes têm a oportunidade de compreender que a Ciência é um saber histórico e provisório (POZO, CRESPO, 2016). Um modo de se fazer isso é valorizar as perguntas propostas pelos estudantes, a fim de que elas façam parte do processo de construção de seus conhecimentos.

A Base Nacional Comum Curricular - BNCC (BRASIL, 2018) evidencia o papel das perguntas dos estudantes em todas as áreas do conhecimento. No que tange o Ensino de Ciências da Natureza, o documento destaca como elemento central atividades investigativas nas quais os estudantes se assumam como sujeitos da sua aprendizagem. Para que isso ocorra, o ensino de Ciências deve oportunizar situações nas quais os estudantes possam "observar o mundo a sua volta e fazer perguntas. Analisar demandas, delinear problemas e planejar investigações" (Ibid, 2018, p. 323). Nesse sentido, "é importante motivá-los com desafios cada vez mais abrangentes, o que permite que os questionamentos apresentados a eles, assim como os que eles próprios formulam, sejam mais complexos e contextualizados" (Ibid, 2018, p. 324). Dada a importância da BNCC e o fato de as perguntas dos estudantes estarem presentes nesse documento, é ratificada/ratifica-se a relevância dessas perguntas para a aprendizagem e para o ensino de ciências. 
Edição Especial: I SSAPEC - Simpósio Sul-Americano de Pesquisa em Ensino de Ciências

ISSN: 2595- $4520 \quad$ Vol. 4, n. 3. 2021

As perguntas dos estudantes possuem reconhecido valor nos processos de ensino e aprendizagem. Desempenha um importante papel na aprendizagem ativa, uma vez que propor perguntas possibilita ao estudante participar de modo efetivo nesse processo. Logo, educadores ressaltam a importância das perguntas dos estudantes nos processos de ensino e aprendizagem e o número de pesquisas nessa área está crescendo (CARDOSO; ALMEIDA, 2014).

Conforme Souza (2006), as perguntas dos estudantes são um meio eficiente para identificar os problemas conceituais, pois podem ser detectados equívocos que outros métodos, como os que são baseados nos questionamentos dos professores, não revelariam. O erro é um indicativo de como está o processo de ensino e pode auxiliar os estudantes a se apropriarem dos conceitos científicos corretos (BARTELMEBS; HARRES, 2017).

Nas perguntas que os estudantes propõem, é possível verificar os problemas conceituais existentes, em relação aos assuntos em estudo. Este problema conceitual pode ser entendido como uma representação de um determinado conceito diferente do aceito no campo científico.

Nesse estudo, utilizaremos o termo problema conceitual, e não erro conceitual, por compreendermos que a palavra erro remete a uma ideia positivista de ensino, na qual o professor é o detentor da verdade, e cabe ao estudante memorizar e reproduzir a fala do professor. Nessa perspectiva, elaborou-se a seguinte pergunta norteadora: $D e$ que modo as perguntas propostas por estudantes Ensino Fundamental e Médio revelam os problemas conceituais que os estudantes têm em relação aos conceitos científicos? Portanto, o objetivo foi compreender como as perguntas propostas por estudantes de Ensino Fundamental e Médio revelam os problemas conceituais que os estudantes têm em relação aos conceitos científicos.

\section{AS PERGUNTAS DOS ESTUDANTES E OS PROBLEMAS CONCEITUAIS}

Na sala de aula, as perguntas dos professores são mais frequentes. Eles utilizam as perguntas para rever conceitos, iniciar e redirecionar discussões, organizar e dirigir as atividades que são realizadas em sala de aula, como também para controlar o comportamento dos estudantes (SOUZA, 2006). Os estudantes perguntam quando têm 
Edição Especial: I SSAPEC - Simpósio Sul-Americano de Pesquisa em Ensino de Ciências

ISSN: 2595- $4520 \quad$ Vol. 4, n. 3. 2021

dúvidas ou quando desejam expandir o conhecimento que já possuem. Na sala de aula, os estudantes perguntam pouco, apenas um número muito pequeno faz perguntas espontaneamente (ALMEIDA, 2012).

Nas aulas tradicionais, os professores e estudantes adotam um contrato didático, sendo que quem ensina é quem propõe as perguntas, e quem aprende as responde. Nesse sentido, as perguntas dos estudantes servem apenas para solicitar esclarecimentos de algo que não foi compreendido (SANMARTÍ; BARGALLÓ, 2012). Entretanto, as perguntas dos estudantes possuem potencial para conduzir o processo de ensino e auxiliar na aprendizagem. Diversas pesquisas revelam resultados positivos considerando as perguntas dos estudantes como ponto de partida para o que pode ser trabalhado nas aulas de Ciências (SPECHT; RIBEIRO; RAMOS, 20017; GALLE, 2016; GALLE; PAULETTI; RAMOS, 2016; PAULETTI, et al., 2016; GALLE, et al., 2015; THOMAZ; RAMOS, 2017; SPECTH, 2017; MERTINS, 2019; MERTINS; RAMOS, 2019; MERTINS; GALLE; SILVA, 2020).

$\mathrm{O}$ ato de questionar permite ensinar e aprender. "As perguntas dos alunos abrem uma oportunidade perfeita para ensinar, bem como para aprender. Cada vez que o aluno ousa questionar, a sua mente abre-se para a aprendizagem e esta é uma abertura perfeita para o ensino" (SOUZA, 2006, p.111). Nesse sentido, cada vez que o estudante pergunta, ele está interessado em aprender, e esse é o momento oportuno para que o professor possa ensinar.

Para Vygotsky (1991), a aprendizagem é social, mediada pela linguagem e pode ocorrer na zona de desenvolvimento proximal (ZPD), que corresponde à distância entre o nível de desenvolvimento real, o que o estudante consegue fazer sozinho, e o nível de desenvolvimento potencial, ou seja, o que o estudante poderá realizar com a ajuda do outro. Dentro dessa perspectiva, as perguntas formuladas pelos estudantes podem apontar o nível de desenvolvimento real, ou seja, o que o estudante já compreende. A partir disso, o professor poderá adotar estratégias de ensino que contemplem a utilização das perguntas dos estudantes dentro da zona de desenvolvimento proximal.

Para os estudantes, a proposição de perguntas possibilita que eles sejam capazes de: i) direcionar a aprendizagem e a construção de seu conhecimento próprio; ii) discutir e debater assuntos em sala de aula; iii) monitorar o processo de autoavaliação da sua compreensão; e iv) aumentar a motivação e o interesse (CHIN; OSBORNE, 2008). Para 
os professores, as perguntas dos estudantes podem apresentar diversas possibilidades para o ensino de Ciências: i) revelam os conhecimentos iniciais dos estudantes (RAMOS, 2008); ii) apontam os interesses dos estudantes em relação à aprendizagem (TORT; MÁRQUEZ; SANMARTÍ, 2013); iii) estimulam o desenvolvimento do pensamento complexo e da interdisciplinaridade (THOMAZ; RAMOS, 2017); iv) permitem acompanhar o processo de complexificação da linguagem do estudante (MORAES, 2007; BARGALLÓ, 2005); v) podem iniciar a pesquisa em sala de aula (MORAES; GALIAZZI; RAMOS, 2012); e vi) revelam os problemas conceituais (SOUZA, 2006).

Ao propor uma pergunta, o estudante expressa seu conhecimento sobre o assunto, e, com isso, pode apresentar problemas conceituais em relação aos assuntos em estudo. Como já mencionado no texto, utilizaremos o termo problema conceitual em vez de erro conceitual. Contudo, apresentamos o que Furió, Solbes e Carrascosa (2006, p. 65), definem como erro conceitual:

[...] resposta errada que afeta um conceito científico específico e que responde à existência na mente do sujeito que o expressa, de uma representação desse conceito que é diferente da aceita dentro do campo teórico de conhecimentos científicos em que se está trabalhando.

Neste estudo, entendemos o problema conceitual como uma representação de um determinado conceito diferente do aceito no campo científico. Souza (2006) entende que utilizar as perguntas dos estudantes para identificar os problemas conceituais pode ser um meio mais eficiente que outros métodos utilizados pelos professores na sala de aula, como os que são baseados no questionamento dos professores. Em testes de avaliação, por exemplo, os estudantes tendem a colocar a resposta correta, ou seja, o que o professor espera que ele responda.

Durante o processo de escolarização, os estudantes adquirem conhecimentos resultantes das suas experiências e do modo como compreendem a realidade em que vivem. Devido a isso, os estudantes podem desenvolver concepções alternativas sobre os conceitos científicos (FURIÓ; SOLBES; CARRASCOSA, 2006).

A expressão "ideias dos alunos", para se referir a esses conhecimentos, é utilizada por Bartelmebs e Harres (2017). Quando a criança inicia o processo de escolarização, ela traz conhecimentos que resultam das suas experiências e do modo como elas compreendem o mundo em que vivem. Souza (2006) afirma que os estudantes 
Edição Especial: I SSAPEC - Simpósio Sul-Americano de Pesquisa em Ensino de Ciências

ISSN: 2595- $4520 \quad$ Vol. 4, n. 3. 2021

desenvolvem naturalmente esquemas conceituais os quais são produtos das suas experiências. $\mathrm{Na}$ escola, durante o processo de construção do conhecimento, é necessário que esses esquemas informais se modifiquem para esquemas formais, de modo que as concepções alternativas ou "ideias dos estudantes" se aproximem dos conceitos científicos.

Durante esse processo, podem surgir os problemas conceituais. Portanto, identificar esses problemas é importante para que os estudantes se apropriem dos conceitos científicos corretos, além de ser um indicativo de como está o processo de ensino do professor. Por isso, no processo pedagógico, o erro deve ser visto como um sintoma e não como um mal (BARTELMEBS; HARRES, 2017).

Nesse sentido, as perguntas dos estudantes são um meio eficiente para indicar problemas conceituais. O professor, ao fazer uso das perguntas dos estudantes, pode direcionar a aprendizagem no sentido de reconstruí-los.

\section{PROCEDIMENTOS METODOLÓGICOS}

A pesquisa é de natureza qualitativa (FLICK, 2009) e configurou-se como um estudo de caso (YIN, 2015). Conforme Gray (2014, p. 137), "O principal foco da pesquisa é entender as formas como as pessoas agem e explicar suas ações", nesse sentido o pesquisador qualitativo busca descrever, interpretar e compreender fenômenos. Nesse tipo de pesquisa, a diversidade e a perspectiva dos participantes são consideradas, de modo que o pesquisador é "parte explícita da produção do conhecimento" (FLICK, 2009, p. 25), assim a subjetividade do pesquisador e dos participantes do estudo fazem parte do processo de pesquisa.

Participaram da pesquisa 187 estudantes do Ensino Fundamental e Ensino Médio. No $5^{\circ}$ ano do Ensino Fundamental, o grupo foi constituído por 47 meninas e 42 meninos, com média de idade de 10 anos, de quatro turmas, de três escolas públicas, de três cidades do Rio Grande do Sul. No $2^{\circ}$ ano do Ensino Médio, os participantes foram 52 meninas e 46 meninos, com média de idade de 16 anos, de quatro turmas, de duas escolas públicas, de duas cidades do Rio Grande do Sul. Para garantir o anonimato dos participantes, os estudantes foram designados por meio de letras maiúsculas que indicaram a escola (A, B, C, D), nível de ensino (F para Fundamental e M para Médio) 
Edição Especial: I SSAPEC - Simpósio Sul-Americano de Pesquisa em Ensino de Ciências

ISSN: 2595- $4520 \quad$ Vol. 4, n. 3. 2021

e números indicando o estudante e a pergunta. Assim, por exemplo, AM3P11, se refere à escola $\mathrm{A}$, Ensino Médio, estudante 3, pergunta 11.

Para a proposição de perguntas, os estudantes de cada turma observaram um experimento, no qual ocorreu a extinção da chama de uma vela por ação do gás carbônico. No experimento, inicialmente foi acesa uma vela e entornado um recipiente vazio sobre ela, a chama da vela continuou acesa. Após, em outro recipiente, foram colocados $200 \mathrm{~mL}$ de vinagre e, logo após, adicionadas duas colheres de bicarbonato de sódio. Foi observada a formação de efervescência e liberação de gás. Esse gás foi transferido para outro recipiente vazio e entornado sobre a vela acesa, o que ocasionou a extinção da chama da vela.

Após a realização do experimento, cada estudante formulou perguntas sobre seus interesses e dúvidas relacionados ao fenômeno observado. $\mathrm{Na}$ sequência, em cada turma, ocorreu uma discussão sobre as perguntas propostas. Obteve-se um total de 603 perguntas. No $5^{\circ}$ ano do Ensino Fundamental, 89 estudantes propuseram 297 perguntas, no $2^{\circ}$ ano do Ensino Médio foram propostas 306 perguntas por 98 estudantes. Para esse estudo, o corpus foi recortado, com vistas às perguntas que continham problemas conceituais. Portanto, neste estudo, temos 63 perguntas propostas por estudantes do Ensino Fundamental e 40 perguntas dos estudantes de Ensino Médio.

As perguntas foram analisadas por meio da Análise Textual Discursiva (MORAES; GALIAZZI, 2016). O processo de análise ocorreu em três etapas: i) unitarização, faz-se a fragmentação do corpus de análise em unidades de sentido, nesta investigação, cada pergunta constituiu uma unidade de sentido; ii) categorização, as unidades de sentido que apresentam concepções semelhantes são agrupadas em categorias; iii) construção de metatextos, que consiste na elaboração de textos descritivos e interpretativos sobre cada categoria.

\section{RESULTADOS E DISCUSSÕES}

A seguir, são apresentados os resultados da análise em relação aos problemas conceituais presentes nas perguntas dos estudantes. Nas do Ensino Fundamental, foram identificados 68 problemas conceituais em 63 perguntas. Nas do Ensino Médio, identificamos 43 problemas conceituais em 40 perguntas. 


\subsection{Caracterização das perguntas dos estudantes de $5^{\circ}$ ano do Ensino} Fundamental em relação aos problemas conceituais presentes

Em 63 perguntas, foram identificados 68 problemas conceituais. Isso mostra que algumas perguntas tiveram mais de um problema conceitual e corresponde a $22,9 \%$ sobre o total das perguntas formuladas pelos estudantes de $5^{\circ}$ ano do EF. Os estudantes da escola B $(17,2 \%)$ propuseram menos perguntas com problemas conceituais que os estudantes das escolas A $(27,3 \%)$ e C $(26,3 \%)$.

Os problemas conceituais presentes nas perguntas dos estudantes do EF deram origem a quatro categorias emergentes: conceitos relacionados às transformações da matéria (31 perguntas); conceitos relacionados à composição da matéria (15 perguntas); conceitos relacionados à linguagem científica (12 perguntas); e conceitos relacionados aos estados físicos da matéria (10 perguntas).

Referente à categoria conceitos relacionados às transformações da matéria, em 12 perguntas os estudantes não compreendem o conceito de transformação da matéria, como, por exemplo, manifestado na pergunta: "Como o fogo apagou sem nenhum esforço do vinagre e do bicarbonato de sódio?", (BF26P185). Os conceitos relacionados à Química, por ser essa uma disciplina presente no currículo do Ensino Médio, são estudados de modo superficial nos primeiros anos do Ensino Fundamental. No entanto, conceitos relacionados às transformações da matéria, poderiam ser abordados, pois os estudantes, já no início do Ensino Fundamental, têm contato com fenômenos como a decomposição dos alimentos, a fotossíntese e a combustão (MORI; CURVELO, 2014). Se esses conceitos não são discutidos adequadamente nos primeiros anos do ensino de Ciências, os estudantes podem desenvolver concepções alternativas, posteriormente, encontrar dificuldades para a compreensão de outros conceitos químicos (THEODORO; KASSEBOEHMER; FERREIRA, 2009).

Sobre a categoria Conceitos relacionados à composição da matéria, os estudantes se referiram às substâncias e às misturas utilizadas no experimento como ingredientes, objetos, produtos e elementos, como nas perguntas: "Poderíamos usar outros objetos?" (BF3P110); e "Dá para fazer esse experimento com outros produtos, não só com o vinagre e bicarbonato?" (AF16P59). No $5^{\circ}$ ano do EF, conceitos como o de substância, 
Edição Especial: I SSAPEC - Simpósio Sul-Americano de Pesquisa em Ensino de Ciências

ISSN: 2595- $4520 \quad$ Vol. 4, n. 3. 2021

mistura e elemento, que já poderiam ser estudados, nem sempre são abordados nas aulas de Ciências. Zanon e Lottermann (2012) afirmam que, mesmo sem defini-los totalmente, conceitos como o de substância poderiam ser abordados nos anos iniciais do Ensino Fundamental. Para isso, é necessário que o professor utilize uma linguagem acessível aos estudantes, de modo que eles possam começar a significar esse conceito.

Em relação aos Conceitos relacionados à linguagem científica, em 11 perguntas, os estudantes se referiram ao recipiente (garrafa PET) como litro, como mostra a pergunta: "Como o vento passou de um litro para o outro?" (CF13P258). Os estudantes do EF utilizaram a palavra litro para se referir aos recipientes utilizados no experimento, pois, na linguagem do cotidiano dos estudantes, litro pode representar uma garrafa PET.

Sobre os Conceitos relacionados aos estados físicos da matéria, os estudantes manifestaram não compreender o conceito de gás, pois se referiram ao gás produzido na reação entre o vinagre e bicarbonato de sódio como fumaça, vento, vapor e ar, conforme o exemplo: "Mas como o bicarbonato de sódio e o vinagre se misturam e sai o ar deles?" (AF10P33). Verifica-se que os estudantes, ao não terem conhecimento para explicar o que ocorreu na reação química entre o vinagre e o bicarbonato de sódio, relacionaram o que eles visualizaram a algo que eles têm conhecimento, como a fumaça, o vapor, o vento e o ar.

\section{2 Caracterização das perguntas dos estudantes de $2^{\circ}$ ano do Ensino Médio em relação aos problemas conceituais presentes}

Nas perguntas dos estudantes do Ensino Médio, foram identificados 43 problemas conceituais em 40 perguntas, o que corresponde a 14,1\% sobre o total das perguntas formuladas pelos estudantes de $2^{\circ}$ ano do EM. Os estudantes da escola A $(21,2 \%)$ propuseram mais perguntas com problemas conceituais do que os estudantes da escola $\mathrm{D}(7,5 \%)$.

Os problemas conceituais presentes deram origem a quatro categorias emergentes: conceitos relacionados às transformações da matéria (19 perguntas); conceitos relacionados à composição da matéria (14 perguntas); conceitos relacionados à linguagem científica (8 perguntas); e conceitos relacionados aos estados físicos da matéria (2 perguntas).

Na categoria Conceitos relacionados à reação química, os estudantes demonstram não compreender o conceito de reação química, como mostra a pergunta: "Por que

Recebido em: 18/01/2021 
apenas um pouquinho do conteúdo da reação foi suficiente para apagar a vela?"

(AM3P11). As concepções dos estudantes sobre reações químicas foram estudadas por Mortimer e Miranda (1995). Os autores verificaram que os estudantes confundiram transformações químicas com mudanças de estado físico. Isso também foi verificado nas perguntas dos estudantes de EM, como a seguinte: "Por que, ao botar vinagre $e$ bicarbonato, a mistura ferveu?" (AM11P39). Um estudo espanhol, realizado por Furió e Domnínguez (2007), demonstrou que metade dos estudantes participantes da pesquisa não é capaz de diferenciar um processo físico de um químico. Os autores afirmam que esse problema conceitual pode estar relacionado ao conceito que os estudantes atribuem à substância, pois, quando ocorre uma reação química e os estudantes não conseguem diferenciar substância composta de mistura, eles não conseguem definir se a mistura inicial das substâncias se manteve ou se, de fato, ocorreu uma reação química com formação de novas substâncias

Referente à categoria Conceitos relacionados à composição da matéria, o problema mais comum foi em relação à falta de compreensão dos conceitos de substância, mistura e elemento química. Nas perguntas dessa categoria, os estudantes se referiram as substância e misturas utilizados no experimento como elementos, como mostra a pergunta: "Poderia usar algum outro elemento no lugar do vinagre?" (AM33P122). Os estudantes apresentam dificuldades de aprendizagem em relação aos conceitos de substância pura e elemento, essa dificuldade pode estar relacionada ao modo como esses conceitos são ensinados na disciplina de Química (POZO, CRESPO, 2016). Para Furió, Solbes e Carrascosa (2012), a dificuldade que os estudantes têm em diferenciar mistura de substância pode estar relacionada ao fato desses dois termos serem utilizados como sinônimos na linguagem cotidiana. Os autores também afirmam que os estudantes tendem a reduzir a composição da matéria à mistura ou substância composta e substância simples a elemento químico. Desse modo, apresentam dificuldades em distinguir uma mistura de uma substância. Furió e Domínguez (2007) verificaram que dois terços dos estudantes participantes de um estudo não conseguiram diferenciar substância composta de mistura, pois, para eles, ambas são formadas por mais de uma substância simples, que se relaciona com o conceito de elemento químico. Os autores afirmam que, mesmo com todo o processo de escolarização, muitos estudantes tendem a continuar pensando de modo similar ao paradigma Aristotélico, no qual toda a matéria é formada por elementos. 
Ainda na categoria Conceitos relacionados à composição da matéria, nas perguntas, os estudantes também se referiram ao vinagre e ao bicarbonato de sódio como componentes e ingredientes e produtos. Além disso, confundiram produto com fórmula, como na pergunta: "Qual fórmula que se formou do vinagre e bicarbonato?" (DM26P233). De acordo com Furió e Domínguez (2007), a maioria dos estudantes associa o significado de substância química a material ou produto, pois essa compreensão se dá em nível macroscópico. Nas perguntas, os estudantes do Ensino Médio se referiram às substâncias e misturas como produtos e ingredientes, isso demonstra que eles não estão apropriados de uma linguagem científica, pois ainda utilizam a linguagem do cotidiano, como quando utilizam a palavra ingrediente para referir-se a farinha ao preparar uma receita, por exemplo. No cotidiano, produto está associado a algo que foi produzido, enquanto na linguagem Química, produto representa o produto de uma reação química.

Referente à categoria Conceitos relacionados à linguagem científica, os problemas conceituais estão relacionados ao modo como os estudantes não utilizam a linguagem científica, como na pergunta: "Por que a vela apaga quando é aproximado o litro?” (DM30P238). Nessa pergunta, o estudante se referiu ao recipiente utilizado como litro. No cotidiano, o termo litro é utilizado para se referir a uma garrafa PET, porém, na Ciência, litro representa uma unidade de medida de volume.

Sobre a categoria Conceitos relacionados aos estados físicos da matéria, os estudantes demonstraram não compreender a diferença entre gás e vapor, pois em suas perguntas, referem-se ao dióxido de carbono tanto como gás quanto como vapor. Essa dificuldade em fazer essa diferenciação pode estar relacionada à falta de compreensão que os estudantes possuem em nível microscópico da matéria. Visualmente, gás e vapor são semelhantes, porém, na Química, gás é um estado físico da matéria, e vapor “[...] é a fase gás de uma substância abaixo de sua temperatura crítica" (ATKINS; JONES, 2012, p. 343).

\subsection{Comparação entre os problemas conceituais presentes nas perguntas dos} estudantes do $5^{\circ}$ ano do Ensino Fundamental e do $2^{\circ}$ ano do Ensino Médio

A partir da comparação entre as categorias emergentes relacionadas aos problemas conceituais das perguntas dos estudantes do $5^{\circ}$ ano do Ensino Fundamental e do $2^{\circ}$ ano do Ensino Médio, foi elaborado o gráfico da Figura 1. 
Figura 1: gráfico da comparação entre os problemas conceituais das perguntas de estudantes de $5^{\circ}$ ano do Ensino Fundamental e $2^{\circ}$ Ano do Ensino Médio

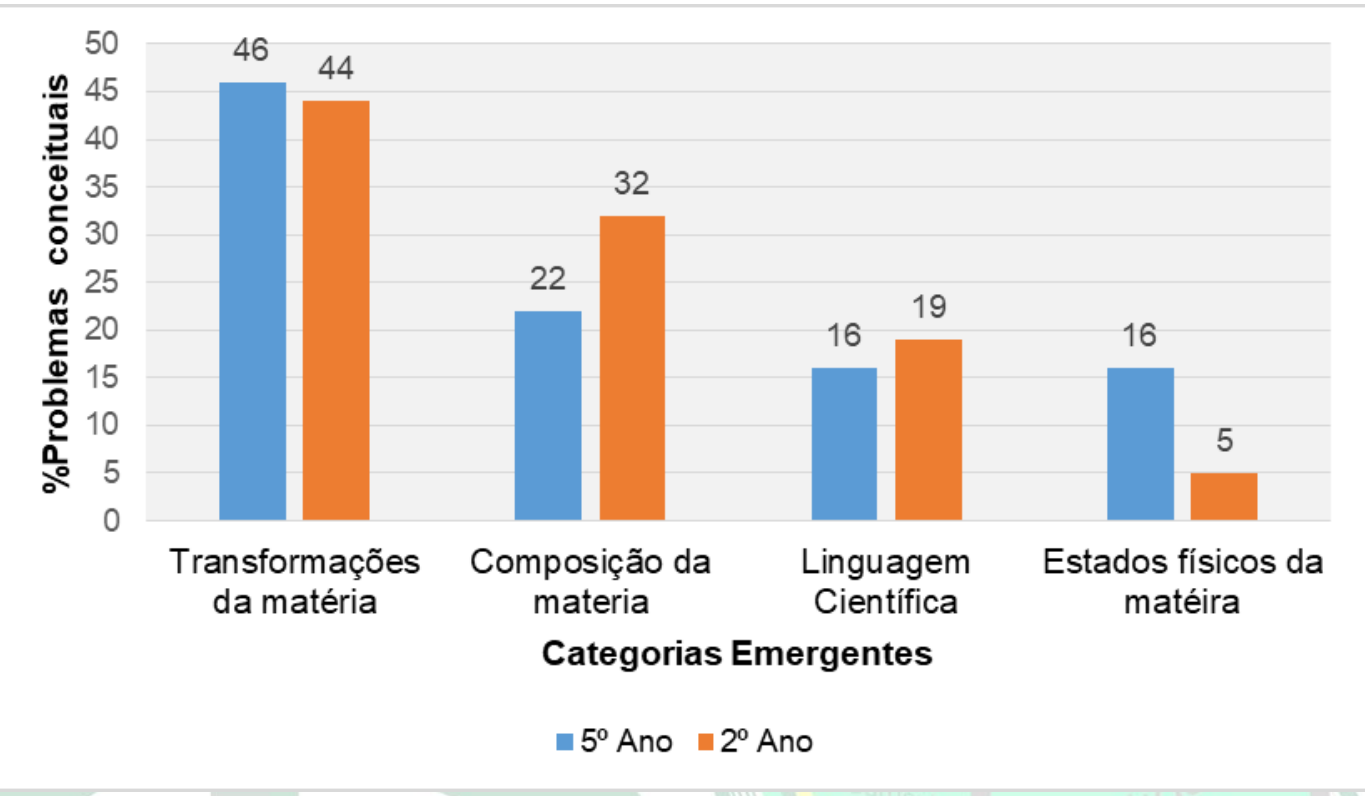

Fonte: Elaborado pelos autores a partir dos dados.

Em ambos os níveis de ensino, as perguntas relacionadas às transformações da matéria foram as que apresentaram mais problemas conceituais. No $5^{\circ}$ ano do Ensino Fundamental, os conceitos relacionados à Química são pouco estudados, pois essa disciplina só é apresentada no $9^{\circ}$ ano do Ensino Fundamental. No entanto, já no início do Ensino Fundamental são estudados fenômenos que ocorrem no cotidiano como a combustão, a decomposição da matéria orgânica e a fotossíntese, de modo que conceitos básicos de química poderiam ser abordados (MORI; CURVELO, 2014).

Nas perguntas, os estudantes do Ensino Fundamental demonstraram não compreender o conceito de transformação da matéria, como exemplo, não conseguiram distinguir bolhas de espuma, referiram-se à efervescência como explosão, fermentação, fervura e agitação, como descrito na pergunta: "Por que aconteceu a explosão com bicarbonato e vinagre?" (AF3P8). Os estudantes do Ensino Fundamental manifestaram nas perguntas o que eles visualizaram durante a realização do experimento, baseados nas suas experiências concretas. Considerando o senso comum, visualmente, o fenômeno da efervescência é semelhante a uma explosão, porém são conceitos diferentes. Para, Kasseboehmer e Ferreira (2009), quando esses conceitos, nas séries iniciais do Ensino Fundamental, não são abordados corretamente, é possível que os 
estudantes desenvolvam concepções alternativas que poderão dificultar posteriormente a compreensão de outros conceitos químicos.

Ainda sobre a categoria transformações da matéria, os estudantes de $2^{\circ}$ ano do Ensino Médio, em geral, já teriam estudado esses conceitos em diferentes assuntos da disciplina de química. No entanto, os estudantes demonstraram ter dúvidas em relação às transformações físicas e químicas, confundindo mistura com reação química. Também, demonstraram problemas conceituais em relação à estequiometria. $\mathrm{Na}$ Espanha, uma pesquisa revelou que metade dos estudantes participantes de um estudo não conseguiam diferenciar um processo físico de um químico. Isso pode estar relacionado ao conceito que os estudantes atribuem à substância, pois quando não diferenciam substância composta de mistura, consequentemente, não conseguem definir se a mistura inicial das substâncias se mantém ou se ocorreu uma reação química com formação de novas substâncias (FURIÓ; DOMNÍNGUEZ, 2007).

Em relação à categoria composição da matéria, os estudantes de $2^{\circ}$ ano do Ensino Médio apresentaram mais problemas conceituais. No Ensino Fundamental, os estudantes se referiram às substâncias e misturas, como vinagre e bicarbonato de sódio, como ingredientes, objetos, produtos e elementos. No Ensino Médio, o problema conceitual mais comum foi em relação à falta de compreensão dos conceitos de elemento químico, substância e mistura, como mostram as perguntas: "Poderia usar algum outro elemento no lugar do vinagre?" (AM33P122).

Para o Ensino Fundamental, problemas conceituais com relação à composição da matéria são esperados, pois, em geral, esses conceitos não são abordados nas aulas de Ciências, e, por não estarem apropriados dos termos científicos, os estudantes utilizam a linguagem do cotidiano para se expressar. Sobre o problema conceitual de elemento, apontado pelos estudantes de Ensino Médio, Furió e Domínguez (2007) afirmam que muitos estudantes pensam de modo similar ao paradigma Aristotélico, no qual toda a matéria é formada por elementos. Além disso, que a dificuldade que os estudantes têm em distinguir substância de mistura pode estar relacionada ao fato de que no cotidiano esses dois termos são utilizados como sinônimos (FURIÓ; SOLBES; CARRASCOSA, 2006).

Nas perguntas dos estudantes do Ensino Médio, estes se referiram às substâncias e misturas como componentes, ingredientes, fórmula e produto. Nesse sentido, a não apropriação desses conceitos, no Ensino Médio, pode estar relacionada ao modo de ensino desenvolvido nas escolas, pois atividades que envolvem a memorização e reprodução das definições e dos conceitos não são suficientes para que ocorra a aprendizagem. Para Furió e Domínguez (2007), os estudantes associam o significado de substância química a produto porque essa compreensão ocorre em nível macroscópico. 
Isso pode ocorrer porque os professores, ao introduzirem esses conceitos, não relacionam o campo macroscópico com o microscópico, para realizarem exposições e explicações sobre o comportamento das substâncias. Os autores afirmam que esses conceitos devem ser abordados considerando os elementos históricos de como esses conceitos foram construídos, a fim de que os estudantes compreendam que cada conceito surgiu como resposta a uma pergunta.

Quanto aos conceitos relacionados à linguagem científica, as perguntas evidenciaram uma maior apropriação dos termos científicos pelos estudantes do Ensino Médio, pois, no Ensino Fundamental, 11 estudantes empregaram a palavra litro para se referirem à garrafa PET. Enquanto no $2^{\circ}$ ano do Ensino Médio, somente dois estudantes utilizaram a mesma expressão. Com relação à categoria conceitos relacionados aos estados físicos da matéria, os problemas conceituais dos estudantes do Ensino Médio foram específicos quanto à diferença entre vapor e gás. Os estudantes do Ensino Fundamental, por não estarem apropriados do conceito de gás, relacionaram o gás carbônico produzido pela reação entre o vinagre e o bicarbonato de sódio ao campo macroscópico, compreendem como algo semelhante que eles já visualizaram como a fumaça, o ar, o vento e o vapor.

\section{CONSIDERAÇÕES FINAIS}

O estudo buscou responder à seguinte pergunta norteadora: De que modo as perguntas propostas por estudantes do Ensino Fundamental e Médio revelam os problemas conceituais que os estudantes têm em relação aos conceitos científicos? Com base na análise realizada, pode-se considerar o que segue:

i) os estudantes do Ensino Fundamental propuseram mais perguntas com problemas conceituais do que os estudantes do Ensino Médio. Isso já era esperado, pois, no $5^{\circ}$ ano do Ensino Fundamental, em geral, os conceitos relacionados à Química, como os estados físicos da matéria e as transformações, são estudados superficialmente.

ii) nas perguntas dos estudantes do Ensino Médio, foram verificados problemas conceituais relacionados a conceitos já estudados pelos estudantes na disciplina de Química, como, por exemplo, os conceitos de elemento químico, substância e mistura. Isso pode estar relacionado ao modo como esses conceitos são abordados na disciplina de Química, em atividades que envolvem apenas a memorização e a reprodução de conceitos. Assim, quando o estudante necessita aplicar o conceito, não consegue fazê-lo de modo correto, pois o conceito não foi compreendido.

iii) em ambos os níveis de ensino, a forma como a proposição de ensino é executada está falha. Disso decorre a relevância das perguntas dos estudantes e sua 
utilização como retomada das abordagens em sala de aula, a fim de sanar as compreensões equivocadas.

Portanto, esse estudo corrobora a valoração das perguntas dos estudantes para o ensino de ciências, com ênfase nos problemas conceituais, uma vez que ensinar ciências é dar sentido ao que se estuda e permitir que o estudante amplie seus saberes, de modo a sair do senso comum e ter, de fato, o conhecimento científico com significados e relações pertinentes ao seu cotidiano.

\section{REFERÊNCIAS}

ALMEIDA, Patrícia Albergaria. Can I ask a question? the importance of classroom questioning. Procedia Social and Behavioral Sciences, v. 31, p. 634-638, 2012.

BARGALlÓ, Conxita Márquez. Aprender ciencias a través del lenguaje. Educar. n. 33, p. 27-38, abr./jun., 2005.

BARTELMEBS, Roberta Chiesa; HARRES, João Batista Siqueira. As ideias dos alunos, as ideias dos professores e aprendizagem: uma revisão conceitual. In: MARRANGHELLO, Guilherme Frederico; LINDEMANN, Renata Hernandez. Ensino de ciências na região da campanha: contribuições na formação acadêmico-profissional de professores de Astronomia. 1. ed. Itajaí: Casa Aberta, 2017, p. 11-51.

BRASIL. Ministério da Educação. Secretaria de Educação Básica. Base Nacional Comum Curricular: educação é a base. Brasília: MEC/SEB, 2018.

CARDOSO, Maria José; ALMEIDA, Patrícia Albergaria. Fostering student questioning in the study of photossyntesis. Procedia Social and Behavioral Sciences, v.116, 2014, p. 3776-3780.

CHIN, Christine; OSBORNE, Jonathan. Students' questions: a potential resource for teaching and learning science. Studies in Science Education, v. 44, n. 1, p. 1-39, feb., 2008 .

FLICK, Uwe. Introdução à Pesquisa Qualitativa. 3. ed. Porto Alegre: Artmed, 2009.

FURIÓ, Carles Más.; DOMÍNGUEZ, Consuelo Sales. Problemas históricos y dificultades de los estudiantes en la conceptualización de sustancia y compuesto químico. Enseñanza de las Ciencias, v. 25, n. 2, p. 241-258, 2007.

FURIÓ, Carles Más; SOLBES, Jordi; CARRASCOSA, Jaime. Las ideas alternativas sobre conceptos científicos: tres décadas de investigación: resultados y perspectivas. Alambique: didáctica de las ciencias experimentales, v. 48, n. 1, p. 64-77, 2006.

FURIÓ, Carles Más.; DOMÍNGUEZ-SALES, María Consuelo.; GUISASOLA, Jenaro. Diseño e implementación de una secuencia de enseñanza para introducir los conceptos de sustancia y compuesto químico. Enseñanza de las Ciencias, v. 30, n. 1, p. 113-128, 2012.

GALLE, Lorita Aparecida Veloso. Estudo sobre reconstrução significativa de conteúdos no ensino fundamental por meio de unidade de aprendizagem sobre alimentos. 2016. 211f. Dissertação (Mestrado em Educação em Ciências e Matemática) - Faculdade de Física, PUCRS, Porto Alegre, 2016. 
GALLE, Lorita Aparecida Veloso. et al. A pergunta na aprendizagem em química: identificação de falhas conceituais na linguagem dos estudantes. In: Encontro Nacional de Pesquisa em Educação em Ciências - ENPEC, 2015, Águas de Lindóia. X Encontro Nacional de Pesquisa em Educação em Ciências, 2015, p.1-8.

GAlle, L. A. V.; PAUlETTI, F.; RAMOS, M. G. Pesquisa em Sala de Aula: os interesses dos estudantes manifestados por meio de perguntas sobre a queima da vela. Acta Scientiae, Canoas, v. 18, n. 2, p. 498-516, maio/ago. 2016.

GRAY, David. E. Pesquisa no mundo real [recurso eletrônico]. 2. ed. Porto Alegre: Penso, 2014.

THEODORO, M. E. C.; KASSEBOEHMER, A. C.; FERREIRA, L. H. A evolução do conceito transformação química em livros didáticos de $1^{\mathrm{a}}$ à $4^{\mathrm{a}}$ série do Ensino Fundamental e aprovados pelo PNLD. In: Encontro Nacional de Pesquisa em Educação em Ciências, 2, 2009. Florianópolis. Anais... Florianópolis: UFSC, Nov., 2009.

MERTINS, Simone. Estudo das perguntas de estudantes do Ensino Fundamental e Médio no contexto do ensino e da aprendizagem em Ciências. Dissertação. 2019. 120f. Dissertação (Mestrado em Educação em Ciências e Matemática) - Escola Politécnica, PUCRS, Porto Alegre, 2019.

MERTINS; Simone. GALlE, Lorita Aparecida Veloso; SILVA, Carla Melo da. Pesquisa como princípio educativo: contribuições das perguntas dos estudantes para a aprendizagem de Química. Revista Insignare Scientia - RIS, v. 3, n. 3, p. 190 a 207, nov. 2020.

MERTINS, Simone; RAMOS, Maurivan Güntzel. As perguntas em sala de aula: percepções de estudantes de Ensino Fundamental e Médio. In: Encontro Nacional de Pesquisa em Educação em Ciências - ENPEC, 2019, Natal. XII Encontro Nacional de Pesquisa em Educação em Ciências, 2019, p.1-6.

MORAES, Roque. Participando de jogos de aprendizagem: a sala de aula com pesquisa. In: Anais do VII Seminário "Escola e Pesquisa um encontro possível". Universidade de Caxias do Sul, Caxias do Sul, 2007.

MORAES, Roque; GALIAZZI, Maria do Carmo. Análise Textual Discursiva. 3. ed. Ijuí: Editora UNIJUÍ, 2016.

MORAES, Roque; GALIAZZI, Maria do Carmo; RAMOS, Maurivan Güntzel. Pesquisa em sala de aula: fundamentos e pressuposto. In: MORAES, Roque; LIMA, Valderez Marina do Rosário (org.). Pesquisa em sala de aula: tendências para a educação em novos tempos. Porto Alegre: EDIPUCRS, p.11-20, 2012.

MORI, Rafael Cava; CURVELO, Antonio Aprigio da Silva. Química no ensino de Ciências para as series iniciais: uma análise de livros didáticos. Ciência \& Educação, Bauru, v. 20, n. 1, p. 243-258, 2014.

MORTIMER, Eduardo Fleury; MIRANDA, Luciana Campos. Concepções dos estudantes sobre reações químicas. Química Nova na Escola, n. 2, p. 23-26, nov., 1995.

PAULETTI, Fabiana. et al. Pesquisa em sala de aula: análise das perguntas de estudantes da Educação Básica sobre o lixo. In: Encontro Nacional de Ensino de Química - ENEQ, 2016, Florianópolis. XVIII Encontro Nacional de Ensino de Química, 2016. v. 1. p. 1-9. 
POZO, Juan Ignácio; CRESPO, Miguel Angel Gomez Crespo. A aprendizagem e o ensino de ciências: do conhecimento cotidiano ao conhecimento científico. 5.ed. Porto Alegre: Artmed, 2009.

RAMOS, Maurivan Guntzel. A Importância da problematização no conhecer e no saber em ciências. In: GALIAZZI, M. C. et al. (Org.). Aprender em rede na educação em ciências. Ijuí: Editora UNIJUI, 2008, p. 57-75.

SANMARTÍ, Neus.; BARGALLÓ, Conxita Márquez. Enseñar a plantear preguntas investigables. Alambique, n. 70, p. 27-36, ene., 2012.

SOUZA, F. Perguntas na Aprendizagem de Química no Ensino Superior. (2006).

530 f. Tese (Doutorado em Didáctica) - Departamento de Didáctica e Tecnologia Educativa, Universidade de Aveiro, Aveiro, 2006

SPECHT, Cristiano Centeno; RIBEIRO, Marcus Eduardo Maciel; RAMOS, Maurivan Güntzel. Estudo das perguntas de professores e estudantes em aulas de Química. Revista Thema, v. 14, p. 225-242, 2017

SPECHT; Cristiano Centeno. A valorização das perguntas por professores em aulas de química: estudo de casos múltiplos. 2017. 123 f. Dissertação (Mestrado em Educação em Ciências e Matemática) - Faculdade de Física, PUCRS, Porto Alegre, 2017.

THEODORO, Mônica Elizabeth Craveiro; KASSEBOEHMER, Ana Cláudia; FERREIRA, Luiz Henrique. A evolução do conceito transformação química em livros didáticos de $1^{\mathrm{a}}$ à $4^{\mathrm{a}}$ série do Ensino Fundamental e aprovados pelo PNLD. In: Encontro Nacional de Pesquisa em Educação em Ciências, 2, 2009. Florianópolis. Anais... Florianópolis: UFSC, Nov., 2009.

THOMAZ, Estrella. M.; RAMOS, Maurivan Güntzel. A Análise Textual Discursiva na interpretação do pensamento complexo e interdisciplinar presente nas perguntas dos estudantes. In: $6^{\mathbf{0}}$ Congresso Ibero-Americano em Investigação Qualitativa e 2nd International Symposium on Qualitative Research - CIAIQ 2017, Salamanca, Espanha, v. 3, p.657-666, 2017.

TORT, Montserrat Roca; MÁRQUEZ, Conxita; SANMARTÍ, Neus. Las preguntas de los alumnos: Una propuesta de análisis. Enseñanza de las Ciencias, v. 31, n. 1, p. 95$114,2013$.

VYGOTSKY, Lev Semyonovich. A formação social da mente. São Paulo: Martins Fontes, 1991.

YIN, Robert K. Estudo de caso: planejamento e métodos. [recurso eletrônico]. 5 ed. Porto Alegre: Bookman, 2015. 